\title{
Mapping Heterotopia: Port B's Excavation of Asia in Tokyo
}

\author{
Sharon Hayashi \\ YorkUniversity,hayashi@yorku.ca
}

Keywords: Tokyo, Mapping, Heterotopia, Heterochronia

\begin{abstract}
:
The term mapping can literally mean the pinpointing of coordinates on a map, but also the more general task of taking stock of what can be seen and the frameworks that limit or expand that vision. For French philosopher Jacques Rancière, asking the question 'Where are we?' means two things at once: "how can we characterize the situation in which we live, think and act to-day?" but also, by the same token, "how does the perception of this situation oblige us to reconsider the framework we use to "see" things and map situations, to move within this framework or get away from it?" In other words, "how does it urge us to change our very way of determining the coordinates [not just of the map but] of the "here and now"?"

The Tokyo based collective Port B, led by Akira Takayama, has inventively used tour performances as a process of mapping, of transforming the frameworks that shape our understanding of everyday spaces in the city. Port B's smartphone application Tokyo Heterotopia is a self-guided tour of 13 'locations of difference' that emphasizes not only the spatial but also the historical dimension of mapping. Based on the premise of a fake Asian gourmet tour, it encourages users to reconsider in a tactile way the historical significance, presence and personal histories of Asian immigrants to Tokyo. Users navigate themselves to locations across Tokyo, including Asian restaurants, food stalls, supermarkets, and student dormitories. These nondescript sites are made visible not by markers or monuments but by the user's presence which triggers dramatized stories of personal narratives of migration to Tokyo and their relationship to wider global forces of colonialism, capitalism and postwar independence movements. Tokyo Heterotopia rewrites the history of Asia in Tokyo "media artistically, that is, taking into account the materialities through which history is articulated, not relying on written narrative as the only way of producing historical, temporal knowledge." Tokyo Heterotopia immerses the user not only in the heterogenous elements or 'locations of difference' of the city, but in a heterochronia where the overlooked past can be joined with the experience of the everyday in the present to incrementally re-map our understanding of the city.
\end{abstract}

Bibliography

Rancière, Jacques. "A few remarks on the method of Jacques Rancière.” In parallax, 2009 vol. 15, no. 3, $114-123$.

Parikka, Jussi. "Archaeologies of Media Art: Jussi Parikka in conversation with Garnet Hartz.” CTHEORY, April 1, 2010, http://www.ctheory.net/articles.aspx?id=631 